\title{
Soil-water characteristic curves for collapsing walls of Benggang in a typical granite area of southeast China
}

\author{
Liting Zhang ${ }^{1}$, Shujun Sun ${ }^{1}$, Mengqi Lin ${ }^{1}$, Kaijun Feng ${ }^{1}$, Yue Zhang ${ }^{1}$, Jinshi Lin ${ }^{1}$, Hongli \\ $\mathrm{Ge}^{1}$, Yanhe Huang ${ }^{1}$, and Fangshi Jiang ${ }^{1}$ \\ ${ }^{1}$ Fujian Agriculture and Forestry University
}

September 24, 2021

\begin{abstract}
The water content is a crucial factor in evaluating the causes of Benggang collapse. The soil-water characteristic curve (SWCC) is an important parameter for the quantitative study of soil water content. However, limited research has been carried out on the SWCCs of the Benggang soil profile. We studied two typical collapsing gullies in southeast China and conducted desorption experiments using a pressure plate extractor to analyze the SWCCs of the undisturbed soils of collapsing walls. The results show large variations in the SWCCs for different soil horizons of a collapsing wall that can be accurately fitted by the van Genuchten (VG) model (NSE[?]0.90). With increasing soil depth, the a and $\vartheta$ s parameters of the VG model first decrease and then increase, red soil layer had the highest a and $\vartheta_{\mathrm{s}}$ (the average value of 0.046 and 0.369 , respectively), whereas the $\mathrm{n}$ parameter of the VG model exhibits the opposite trend, sand soil layer had the highest $\mathrm{n}$ (the average value of 1.563). The $\vartheta \mathrm{r}$ parameter of the VG model decreases with increasing soil depth, red soil layer had the highest $\vartheta \mathrm{r}$ (the average value of 0.194 ). The red soil layer has the highest water-holding capacity, whereas the sandy soil and detritus layers have lower water-holding capacities. The SWCCs are related to the soil material composition, particle composition and porosity. The gravel content and the particle morphology (the aspect ratio, sphericity, and specific surface area) are also the significant influence factors for the SWCC that cannot be neglected. The difference among the SWCCs for the soil profiles of collapsing walls can be used to explain the mechanism for the collapse of collapsing wall. The results of this study provide a theoretical basis for understanding the process of the collapse of collapsing wall in Benggang in southeast China.
\end{abstract}

\section{Hosted file}

Main document.docx available at https://authorea.com/users/435265/articles/538414-soilwater-characteristic-curves-for-collapsing-walls-of-benggang-in-a-typical-granite-areaof-southeast-china 


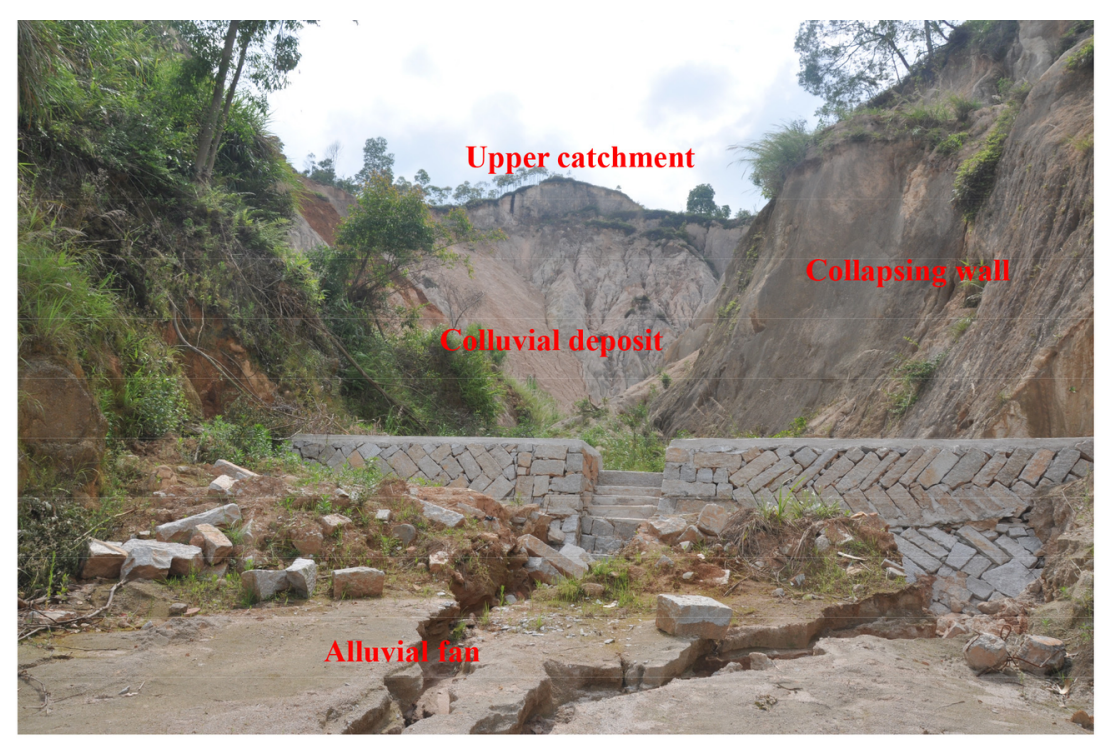

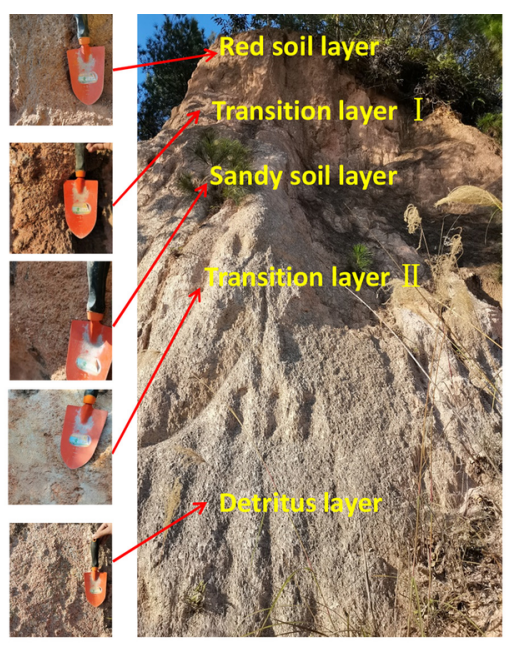

(a)

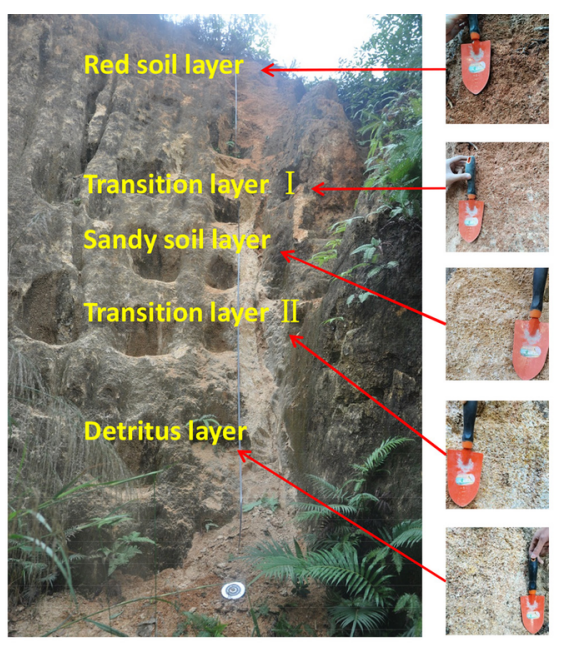

(b) 


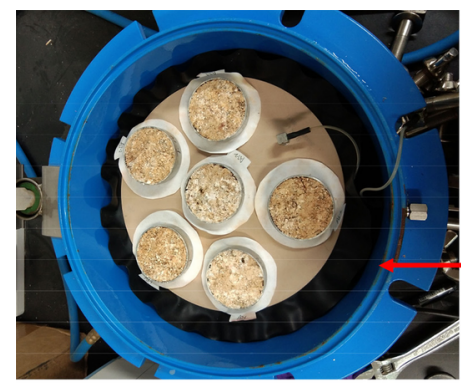

(a)

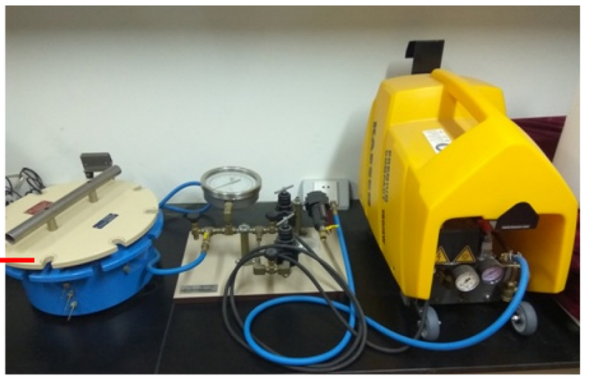

(b)

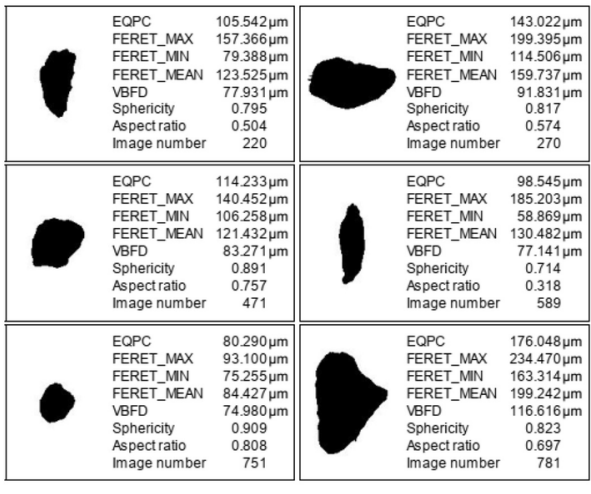

(a)

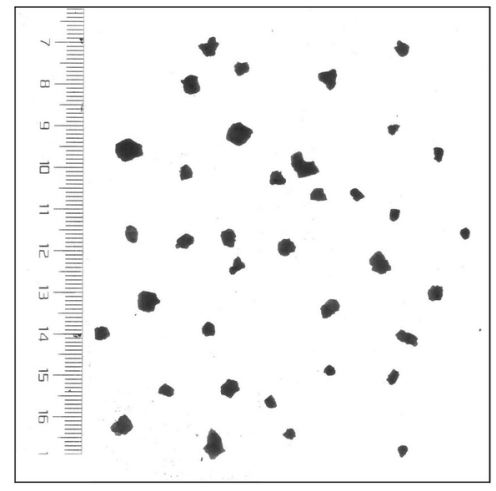

(b) 

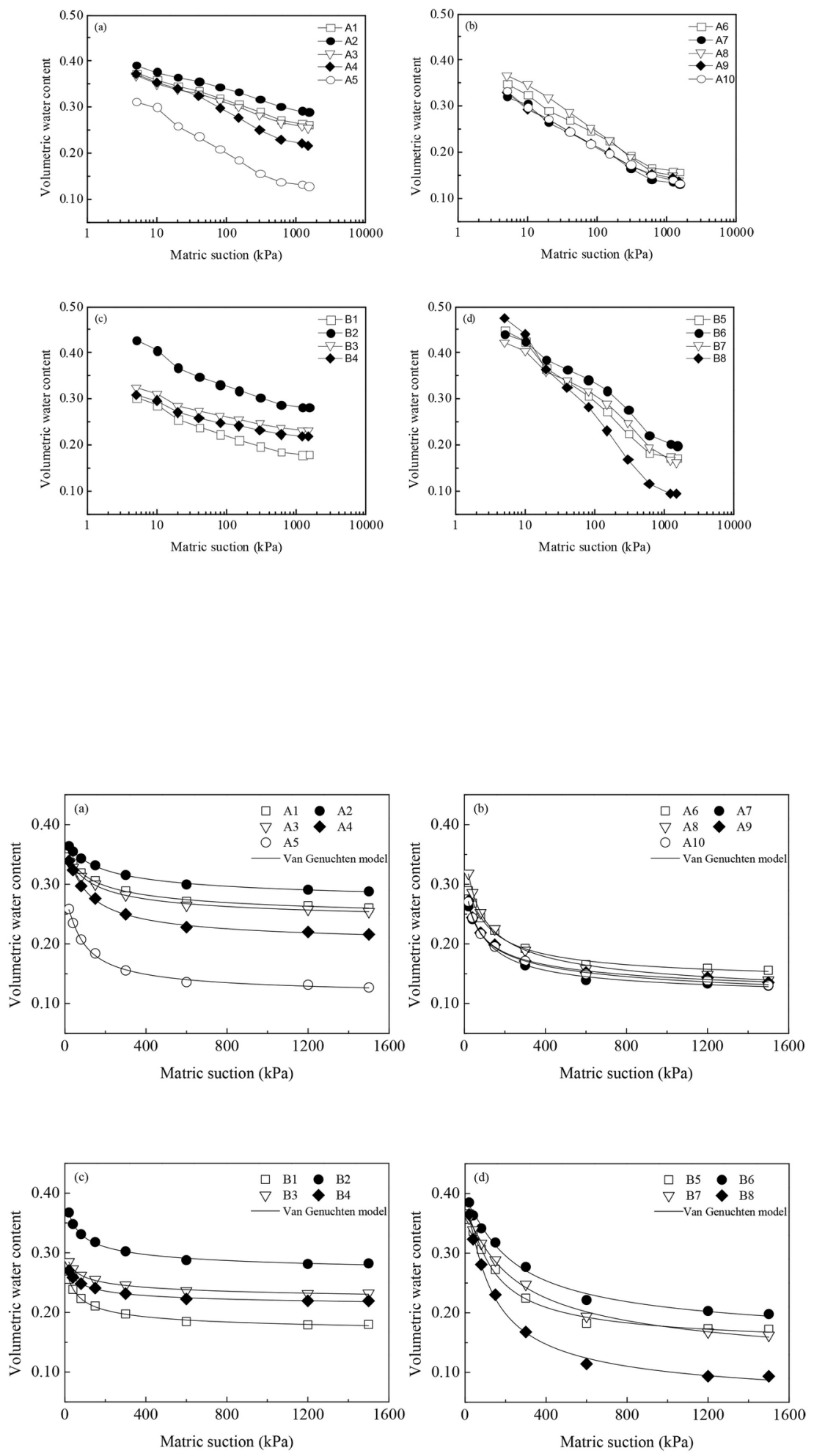

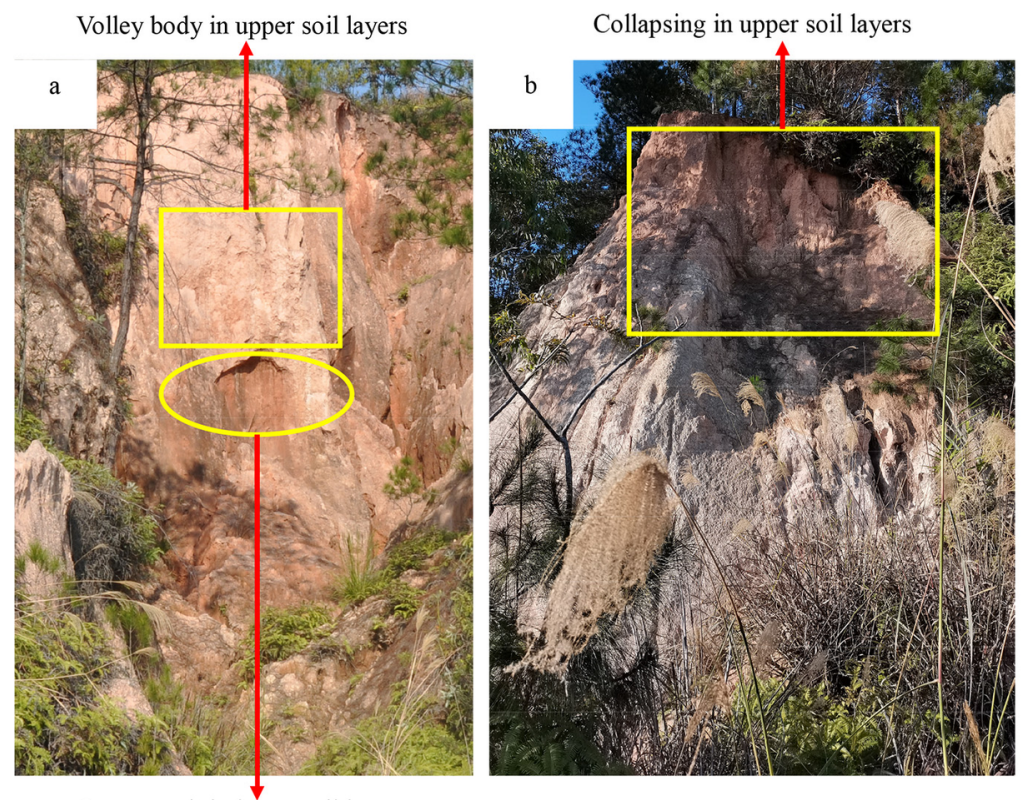

Concave pit in lower soil layers

\section{Hosted file}

20210410 tables - \begin\{CJK\}\{UTF8\}\{gbsn\}. \end\{CJK\} \selectlanguage\{english\}doc available at } https://authorea.com/users/435265/articles/538414-soil-water-characteristic-curves-forcollapsing-walls-of-benggang-in-a-typical-granite-area-of-southeast-china 